\title{
Analisis Kepuasan Wisatawan Telaga Sarangan Magetan Berdasarkan Tourism Experience
}

\author{
Bambang Suyono \\ Program Studi Manajemen, Universitas Merdeka Madiun, Jl. Serayu No.79, Madiun, 63133 \\ E-mail: bambangsuyono@unmer-madiun.ac.id
}

\begin{abstract}
The research on the Analysis of Tourist Satisfaction of Lake Sarangan Magetan Based on Tourism Experience takes the object of tourists visiting the Sarangan Magetan Lake. This study aims to analyze tourist satisfaction after visiting Sarangan lake tourism objects based on tourism experience and knowing what attributes need to be improved to increase tourist satisfaction. Respondents in this study were tourists who visited the Telaga Sarangan tourist attraction, amounting to 70 people. While the data analysis technique in this study uses the Importance Performance Analysis. The research findings show that (1) Priority factors that need to be improved are novelty indicators with question items. I get new experiences after traveling in Sarangan Lake and (2) Factors that need to be maintained and improved such as comfortable traveling in Sarangan Magetan Lake, tourists feel comfortable and happy when visiting, get an unforgettable experience after visiting, get an unforgettable experience and get new experiences, the beautiful Sarangan Lake Magetan tourist attractions, feel amazed at its beauty.
\end{abstract}

Keywords - : tourist satisfaction; tourism experience.

\section{PENDAHULUAN}

Dalam rangka meningkatkan daya saing wisata, pemerintah daerah membuat rumusan strategi kebijakan yang dapat digunakan sebagai roadmap dalam membangun sebuah obyek wisata agar berdaya saing. Kebijakan seyogyanya bersandar pada kondisi semua aspek di kawasan wisata. Beberapa faktor yang dipertimbangkan dalam membuat kebijakan yang tepat antara lain: pengunjung sebagai konsumen, untuk melihat bagaimana tingkat kepuasannya, masyarakat sekitar sebagai pelaku sekaligus pihak yang terdampak oleh kegiatan wisata, hasil evaluasi kebijakan sebelumnya sudahkah memberikan kontribusi, dan apa ukuran keberhasilan dari kebijakan yang telah dilakukan.

Pariwisata mengacu pada Undang-undang Nomor 10 tahun 2009 adalah berbagai macam kegiatan wisata dan didukung berbagai fasilitas serta layanan yang disediakan oleh masyarakat, pengusaha, pemerintah, dan pemerintah daerah (Mudrikah et al, 2014:365). Kabupaten Magetan memiliki beberapa potensi. Potensi-potensi yang dimiliki Kabupaten Magetan antara lain, wisata telaga Sarangan, wisata telaga wahyu, pusat kerajinan kulit, desa wisata di geni langit, kerajinan bambu, wisat alam lainnya seperti mojosemi, cemoro sewu, dan lain sebagainya.

Kenyataan yang ada menunjukkan pengelolaan dan pengembangan produk wisata Kabupaten Magetan dirasakan belum optimal bahkan intensitasnya sangat minim. Permasalahan seperti kurang tertatanya sentra atau zona aktivitas dan fasilitas (belanja dan jajanan / makanan khas) yang berakibat pada kemacetan jalan di tepi telaga dan jalan masuk ke lokasi wisata Telaga Sarangan, belum tersedianya sarana informasi dan interpretasi terhadap atraksi-atraksi wisata (alam, heritage, buatan manusia). Fasilitas lainnya yang belum sepenuhnyamendukung perkembangan kepariwisataan seperti kurangnya kerapihan, kebersihan (higenitas), ketidaktertiban dan lain-lain, belum mencerminkan sebagai pintu gerbang yang bercitra positif, merupakan sebagian kecil permasalahan kepariwisataan yang dihadapi Kabupaten Magetan.

Berdasar latar belakang di atas penelitian ini bertujuan menganalisis kepuasan wisatawan Kabupaten Magetan berdasarkan Tourism Experience dan mengetahui atribut apa saja yang perlu diperbaiki untuk meningkatkan kepuasan wisatawan.

Atas dasar permasalahan di atas maka persoalan yang ingin dipecahkan dalam penelitian ini adalah : Bagaimanakah tingkat kepuasan wisatawan setelah berkunjung pada obyek wisata Telaga Sarangan berdasarkan tourism experience dan mengetahui atribut apa saja yang perlu diperbaiki untuk meningkatkan kepuasan wisatawan?

Berdasar latar belakang di atas penelitian ini bertujuan menganalisis kepuasan wisatawan setelah berkunjung pada obyek wisata telaga Sarangan berdasarkan tourism experience dan mengetahui atribut apa saja yang perlu diperbaiki untuk meningkatkan kepuasan wisatawan.

\section{METODE PENELITIAN}

Pelaksanaan pengambilan data di lapangan dan input data dilakukan bulan Oktober 2018 sampai dengan November 2018. Analisis data dan penyusunan laporan hasil survei dilaksanakan pada bulan Desember 2018.

Populasi adalah wilayah generalisasi yang terdiri atas obyek atau subyek yang mempunyai kuantitas dan karakteristik tertentu yang ditetapkan oleh peneliti untuk dipelajari dan kemudian ditarik kesimpulannya (Sugiyono, 2009:389). Dalam 
Website : http://ekomaks.unmermadiun.ac.id/index.php/ekomaks

penelitian ini yang menjadi populasi adalah wisatawan yang berkunjung ke obyek Wisata Telaga Sarangan. Sedangkan Sampel adalah bagian dari jumlah dan karakteristik yang dimiliki oleh populasi tersebut (Sugiyono, 2009:116).

Mengingat jumlah populasi yang besar maka perlu diambil sampel. Teknik yang digunakan adalah Accidential Sampling, dimana setiap responden yang dijumpai pada saat penelitian dijadikan responden penelitian. Waktu penelitian (penyebaran kuesioner) ditetapkan selama 1 minggu, dengan asumsi setiap 1 hari diperoleh 10 orang wisatawan, sehingga selama 7 hari diperoleh responden penelitian sejumlah 70 orang. Survei dilaksanakan pada tanggal 8 sampai 14 Oktober 2018.

Berkenaan dengan penetapan responden dalam penelitian ini, lebih lanjut dijelaskan oleh Suharsimi Arikunto (2001:107) bahwa: "apabila subyeknya lebih dari 100 (seratus) orang maka sebaiknya diambil antara 10\%-15\% atau 20\%-25\% atau lebih, sedangkan jika subyeknya kurang dari 100 orang, maka sebaiknya diambil seluruhnya. Mengingat jumlah populasi dalam penelitian ini kurang dari 100, maka tidak perlu diambil sampel penelitian, sehingga penelitian ini merupakan penelitian populasi dengan jumlah resonden sebesar 70 orang.

Teknik analisis data pada penelitian ini menggunaan Matrik Kepuasan Kepentingan (Importance performance analysis). Menurut Tjiptono (2011) dalam Jurnal Oskar (2014) teknik ini dikemukakan pertama kali oleh Martilla dan James pada tahun 1977 dalam artikel mereka "ImportancePerformance Analysis" yang dipublikasikan di Journal of Marketing. Pada teknik ini, responden diminta untuk menilai tingkat kepentingan dan kinerja perusahaan, kemudian nilai ratarata tingkat kepentingan dan kinerja tersebut dianalisis pada Importance Performance Matrix, yang mana sumbu x mewakili persepsi sedangkan sumbu y mewakili harapan.

\section{III.PEMBAHASAN HASIL PENELITIAN}

\section{A. Obyek Wisata Telaga Sarangan}

Telaga sarangan adalah danau kecil yang juga biasa disebut telaga pasir. Sebuah telaga alam yang terletak di kaki Gunung Lawu, Kecamatan Plaosan, Kabupaten Magetan, Jawa Timur. Telaga Sarangan terletak di lereng Gunung Lawu (3.265m) yang memiliki keindahan alam pegunungan nan elok. Telaga ini berjarak sekitar 16 kilometer dari arah barat kota Magetan dan sekitar 5 kilometer dari arah tawangmangu. Telaga ini juga mempunyai luas sekitar 30 hektar dan mempunyai kedalaman 28 meter. Telaga sarangan ini adalah objek wisata andalan di kota tersebut. Untuk lebih menikmati keindahan telaga tersebut, pengunjung juga bisa berkuda dan mengendarai kapal cepat berkeliling telaga sarangan tersebut. Di telaga Sarangan juga terdapat hidangan makanan khas yang dijajakan oleh penjual di sekitar telaga tersebut, yaitu sate kelinci. Sate ini biasanya di hidangkan dengan lontong dan sambal kacang. Satu porsi sate kelinci biasanya di hargai sekitar 7.000-10.000. di sekitar telaga juga banyak kios-kios yang menjual hasil hasil home industri setempat yang mampu memproduksi kerajinan-kerajinan souvenir seperti kerajinan kulit, kerajinan sepatu dari kulit, kerajinan anyaman bambu, dll. Ada juga produk makanan khas seperti empeng mlinjo dan lempeng (krupuk puli yang terbuat dari nasi) yang di kenal dengan sebutan lempeng Magetan.

\section{B. Analisa Data}

\section{Variabel Tourism Experience}

Setelah menyebarkan kuesioner kepada responden penelitian, selanjut-nya melakukan tabulasi data dengan menggunakan excel dan kemudian mencari rata-rata dari setiap indikator atau item yang ada yang akan ditunjukkan pada tabel berikut ini.

Tabel 1. Rata-rata Skor Indikator Variabel Tourism Experience

\begin{tabular}{lclcc}
\hline Variabel dan Indikator & No. & \multicolumn{1}{c}{ Pertanyaan } & Kepentingan & Kinerja \\
\hline Tourism Experience & & & 3.41 & 3.33 \\
\hline 1. Kenyamanan & 1 & Saya merasa nyaman berwisata di Telaga Sarangan & 3.37 & 3.30 \\
\cline { 2 - 5 } & 2 & $\begin{array}{l}\text { Saya merasa rileks setelah berkunjung ke obyek wisata Telaga } \\
\text { Sarangan }\end{array}$ & 3.37 & 3.23 \\
\hline 2. Pendidikan & 3 & $\begin{array}{l}\text { Saya mendapatkan pengetahuan baru selama berwisata ke } \\
\text { obyek wisata telaga sarangan }\end{array}$ & 3.45 & 3.39 \\
\hline 3. Hedonis & 4 & $\begin{array}{l}\text { Saya merasa senang ketika berkunjung di obyek wisata Telaga } \\
\text { Sarangan }\end{array}$ & 3.41 & 3.28 \\
\cline { 2 - 5 } & 5 & $\begin{array}{l}\text { Saya mendapat pengalaman yang tidak terlupakan setelah } \\
\text { berkunjung di Telaga Sarangan }\end{array}$ & 3,43 & 3.30 \\
\hline 4. Novelty & 6 & $\begin{array}{l}\text { Saya mendapatkan pengalaman baru setelah berwisata di } \\
\text { Telaga Sarangan }\end{array}$ & 3.31 & 3.08 \\
\hline 5. Pengakuan & 7 & Pelayanan tempat pariwisata di telaga Sarangan sangat bagus & 3.08 \\
\hline 6. Relasional & 8 & $\begin{array}{l}\text { Masyarakat di sekitar obyek wisata Telaga Sarangan sangat } \\
\text { ramah }\end{array}$ & 3.30 & 2.87 \\
\hline 7. Keamanan & 9 & Saya merasa aman ketika berwisata di Telaga Sarangan & 3.46 & 3.33 \\
\hline 8. Keindahan & 10 & Tempat pariwisata di Telaga Sarangan Sangat Indah & 3.49 & 3.30 \\
\cline { 2 - 5 } & 11 & $\begin{array}{l}\text { Saya merasa kagum ketika terhadap keindahan obyek wisata } \\
\text { Telaga Sarangan }\end{array}$ & 34.07 & 35.49 \\
\hline
\end{tabular}


Skor indikator kenyamanan, pendidikan, hedonis, novelty, pengakuan, relasional, keamanan, dan keindahan memiliki total rata-rata kepuasan sebesar 37,5 dan total rata-rata harapan sebesar 35,49. Hasil dari total rata-rata kepentingan dan kinerja kemudian dirata-rata kembali dengan perolehan rata-rata dari rata-rata kepentingan sebesar 3,4 sedangkan untuk kinerja sebesar 3,2.

\section{Importance Performance Analysis}

Setelah mengetahui rata-rata setiap indikator kemudian mengolah data menjadi matrix Importance Performance Analysis pada gambar sebagai berikut:

Gambar 1. Importance Performance Matrix

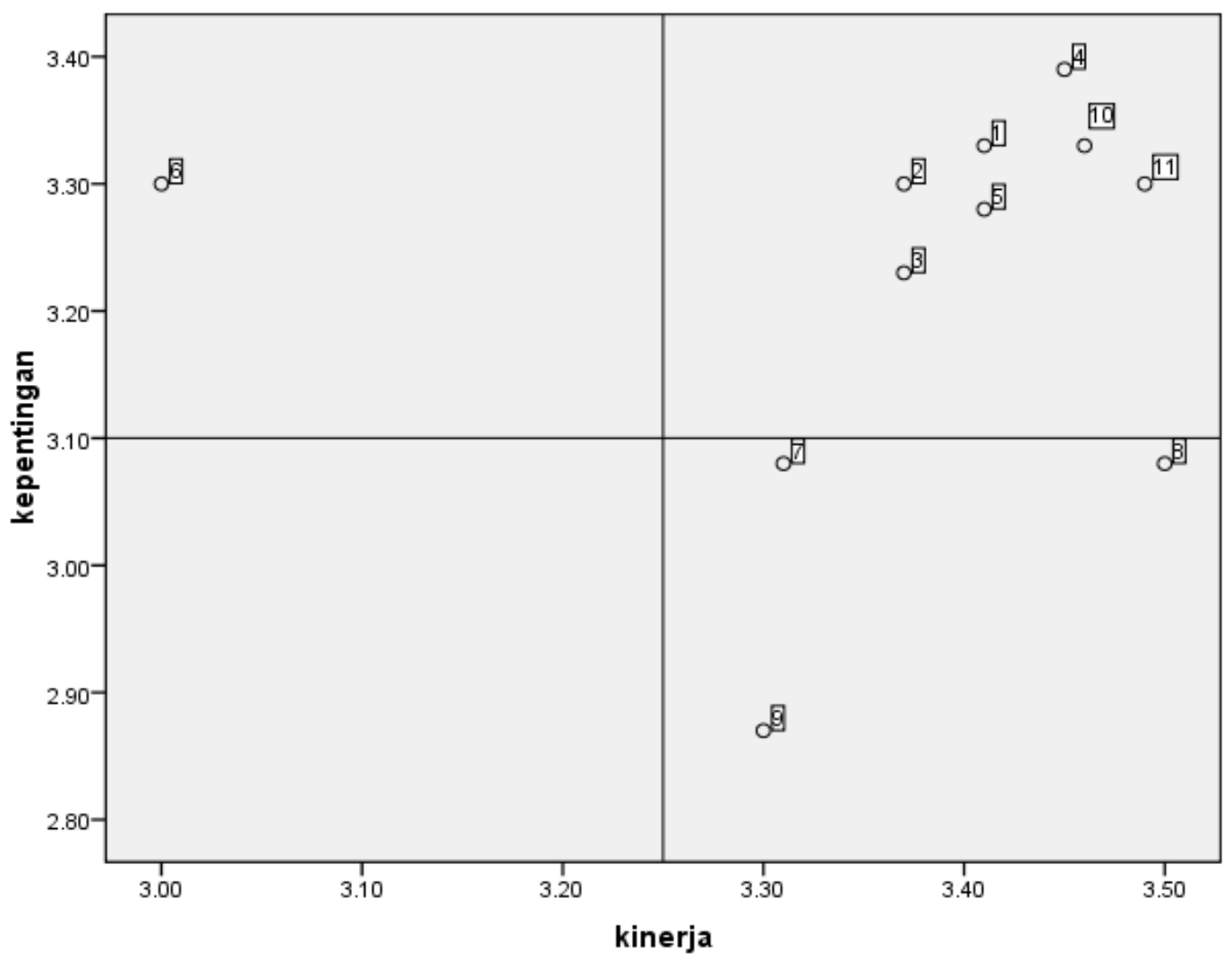

a. Importance Performance Analysis Kuadran 1

Berikut adalah indikator yang berada pada kuadran I

\begin{tabular}{ccc}
\hline \multicolumn{2}{c}{ Tabel 2. Kuadran I } \\
\hline Indikator & No. Item & Pernyataan \\
\hline Novelty & 6 & Saya mendapatkan pengalaman baru setelah berwisata di Telaga Sarangan \\
\hline
\end{tabular}

Kuadran I adalah wilayah yang dianggap penting akan tetapi kinerjanya dinilai belum memuaskan dan belum sesuai yang diharapkan. Indikator yang terdapat pada kuadran I adalah novelty, artinya bahwa wisatawan sebagai responden belum mendapatkan pengalaman baru setelah berwisata di Telaga Sarangan Kabupaten Magetan sesuai dengan apa yang diharapkan.

b. Importance Performance Analysis Kuadran II

Berikut adalah indikator yang berada pada kuadran II.

\begin{tabular}{lcl}
\multicolumn{1}{c}{ Indikator } & No. Item & \multicolumn{1}{c}{ Tabel 3. Kuadran II } \\
\hline Kenyamanan & 1 & Pernyataan \\
\hline & 2 & Saya merasa nyaman berwisata di Telaga Sarangan Magetan \\
\hline Pendidikan & 3 & $\begin{array}{l}\text { Saya mendapat pengalaman yerkunjung di Telaga Sarangan Magetan } \\
\text { Sarangan Magetan }\end{array}$ \\
\hline Hedonisme & 4 & Saya mendapatkan pengalaman baru setelah berwisata di Telaga Sarangan Magetan \\
\hline
\end{tabular}


Website : http://ekomaks.unmermadiun.ac.id/index.php/ekomaks

\begin{tabular}{lcl}
\hline & 5 & Tempat pariwisata di Telaga Sarangan Magetan Sangat Indah \\
\hline Keindahan & 10 & Saya merasa kagum ketika terhadap keindahan Telaga Sarangan Magetan \\
\hline & 11 & Saya merasa kagum ketika terhadap keindahan obyek wisata Telaga Sarangan \\
\hline
\end{tabular}

Kuadran II adalah wilayah yang dianggap penting dan kinerjanya sesuai dengan apa yang diharapkan. Pada kuadran II dapat dilihat indikator seperti kenyamanan berwisata di Telaga Sarangan Magetan, wisatawan merasa nyaman dan senang ketika berkunjung, mendapat pengalaman yang tidak terlupakan setelah berkunjung, mendapatkan pengalaman yang ridak terlupakan dan mendapatkan pengalaman baru, tempat wisata Telaga Sarangan Magetan indah, merasa kagum terhadap keindahannya. Faktor-faktor tersebut artinya bahwa responden yang berkunjung ke obyek wisata Telaga Sarangan Magetan merasa sudah terpenuhi harapannya dengan beberapa indikator di atas mengenai kenyamanan, pendidikan, hedonis dan keindahan.

c. Importance Performance Analysis Kuadran III

Berikut adalah indikator yang berada pada kuadran III

\begin{tabular}{lcl}
\multicolumn{1}{c}{ Indikator } & No. Item & Tabel 4. Kuadran III \\
\hline Pengakuan & 7 & Pelayanan tempat pariwisata di Telaga Sarangan Magetan sangat bagus \\
\hline Rasional & 8 & Masyarakat di sekitar obyek wisata Telaga Sarangan sangat ramah \\
\hline Keamanan & 9 & Saya merasa aman ketika berwisata di Telaga Sarangan Magetan \\
\hline
\end{tabular}

Kuadran III adalah wilayah yang dianggap kurang penting dan pada kenyataannya kinerjanya tidak tinggi. Indikator pengakuan, rasional dan keamanan tempat wisata di Telaga Sarangan Magetan terdapat pada kuadran III. Artinya bahwa pelayanan, masyarakat yang ramah dan keamanan tidak dirasa cukup penting oleh responden dan kinerja yang di berikan tidak terlalu tinggi.

\section{IV.KESIMPULAN DAN SARAN}

\section{A. Kesimpulan}

Berdasarkan hasil penelitian yang berjudul "Analisis Kepuasan Wisatawan Telaga Sarangan Magetan berdasarkan Tourism Experience" dengan menggunakan metode Importance Performance Analysis, maka dapat diambil beberapa kesimpulan sebagai berikut:

1. Faktor prioritas yang perlu diperbaiki adalah indikator novelty dengan item pertanyaan saya mendapatkan pengalaman baru setelah berwisata di Telaga Sarangan. Komponen penting dari pengalaman wisatawan merupakan pengalaman novelty dimana setiap wisatawan akan merasa terkesan dan selalu teringat pada obyek wisata yang dikunjunginya apabila mempunyai kesan baru atau pengalaman baru yang lain dari yang lain.

2. Faktor yang perlu dipertahankan dan ditingkatkan seperti kenyamanan berwisata di Telaga Sarangan Magetan, wisatawan merasa nyaman dan senang ketika berkunjung, mendapat pengalaman yang tidak terlupakan setelah berkunjung, mendapatkan pengalaman yang tidak terlupakan dan mendapatkan pengalaman baru, tempat wisata Telaga Sarangan Magetan indah, merasa kagum terhadap keindahannya. Artinya bahwa responden yang berkunjung ke obyek wisata Telaga Sarangan Magetan merasa sudah terpenuhi harapannya dengan beberapa indikator di atas mengenai kenyamanan, pendidikan, hedonis dan keindahan.

\section{B. Saran}

Berdasarkan hasil penelitian yang dilakukan maka dapat diambil beberapa saran sebagai berikut:

1. Pemerintah diharapkan memberikan edukasi dan sosialisasi kepada masyarakat sekitar tempat pariwisata di telaga Sarangan Magetan untuk berinteraksi dan berkomunikasi dengan baik kepada wisatawan. Sehingga akan timbul hubungan yang dapat memberikan efek positif bagi lingkungan sekitar tempat pariwisata.

2. Hendaknya pengelola obyek wisata Telaga Sarangan lebih meningkatkan kebersihan di lingkungan sekitar wisata agar wisatawan nyaman ketika berkunjung.

3. Hendaknya penataan pedagang kaki lima di lokasi wisata Telaga Sarangan lebih ditertibkan agar tidak terkesan 'semrawut' dan mengganggu kenyamanan dan ketenangan wisatawan ketika berkunjung.

\section{UCAPAN TERIMA KASIH}

Ucapan terima kasih disampaikan kepada berbagai pihak khususnya kepada Kepala Kesbanglinmaspol Kabupaten Magetan yang telah memberikan ijin penelitian dan meluangkan waktu untuk membantu kelancaran penelitian.Tidak lupa terima kasih juga kami sampaikan kepada rekan-rekan dosen yang telah memberikan saran-saran kritis demi kesempurnaan hasil penelitian ini. Demikian juga terima kasih disampaikan kepada Rektor Universitas Merdeka Madiun yang telah memberikan pendanaan dalam penelitian ini. 
Website : http://ekomaks.unmermadiun.ac.id/index.php/ekomaks

\section{VI.DAFTAR PUSTAKA}

Bagus, I Gusti. 2014. Pengantar Industri Pariwisata. Yogyakarta: CV Budi Utama.

Ebert, Ronald J. \& Ricky W. Griffin. (2016). Bisnis. Jakarta: Erlangga.

Fandy Tjiptono, 2011. Manajemen Jasa, Edisi kedua, Yogyakarta: Penerbit Andi.

Imam Ghozali. 2006. Aplikasi Analisis Multivariate dengan program SPSS, Badan. Semarang: Penerbit Universitas Diponegoro.

Kotler,P. \& Kevin Lane Keller. 2009. Managemen Pemasaran, Edisi Ketiga Belas, Jilid Pertama, Jakarta, Erlangga.

Mudrikah, Alfiah dkk. 2014. Kontribusi Sektor Pariwisata Terhadap Gdp Indonesia Tahun 2004-2009.

Oka A. Yoeti. 2009. Ekonomi Pariwisata: Introduksi, Informasi, dan Implementasi. Penerbit. Kompas. Jakarta.

Oskar, Johan \& Jati Pambudi. 2014. Analisis Kepuasan Pelanggan Dengan Importance Performance Analysis di SBU Laboratory Cibitung PT Sucofindo (persero) Vol IX, No 1, Januari 2014.

Pendit. 2008. Ilmu Pariwisata (Sebuah Pengantar Perdana). Jakarta: PT Pradnya Paramita

Rageh, Ahmed dkk. 2013. Using netnography research method to reveal the underlying dimensions of the customer/tourist experience. Qualitative Market Research: An International Journal, Vol. 16 Iss 2 pp. 126 - 149

Rondonuwu, Giovani. 2014. Jurnal Tingkat Kepuasan Konsumen di Restoran MCDonal's Manado. Kementrian Pendidikan dan Kebudayaan Universitas SAM Ratulangi Fakultas Pertanian Manado.

Sheng, Chieh-Wen dkk. 2013. Tourist experience expectations: questionnaire development and text narrative analysis. International Journal of Culture, Tourism and Hospitality Research, Vol. 7 Iss 1 pp. $93-104$

Sugiyono, 2009. Metode Penelitian Bisnis. Bandung: Alfabeta.

Suharsimi Arikunto. 2011. Prosedur Penelitian Suatu Pendekatan Praktik. Jakarta: Rineka Cipta. 